\title{
Study on the Incidence of Chronic Respiratory Disease in Layer and Broiler Chickens in Ayodhya District of Eastern Uttar Pradesh, India
}

\author{
R.K. Gupta ${ }^{1 *}$, D. Niyogi ${ }^{1}$, J.P. Singh ${ }^{2}$, Sonu Jaiswal ${ }^{3}$, \\ P.K. Chaudhary ${ }^{4}$ and V.K. Varun ${ }^{5}$ \\ ${ }^{1}$ Department of Veterinary Pathology, ${ }^{2}$ Department of Veterinary Medicine, \\ ${ }^{3}$ Department of Veterinary Clinical Complex, ${ }^{4}$ Department of Veterinary Physiology and \\ Biochemistry, C.V.Sc \& A.H, NDUAT, Kumarganj, Ayodhya, Uttar Pradesh-224229, India \\ ${ }^{5}$ Department of Veterinary Clinical Complex, COVAS, SVPUAT, Meerut, \\ Uttar Pradesh-250110, India \\ *Corresponding author
}

\section{Keywords}

Incidence, Chronic respiratory disease, Broiler, Layer, Ayodhya

Article Info

Accepted:

12 July 2019

Available Online:

10 August 2019
The present study was conducted to record the incidence of chronic respiratory disease of layer and broiler birds in Ayodhya district of Eastern Uttar Pradesh. The naturally dead birds from 10 different private farms in Ayodhya district of Eastern Uttar Pradesh was collected for 6 months (October, 2018 to March, 2019). After post-mortem examination, the grossly suspected samples (trachea, air sac and lung) were kept for further histopathological and immunohistochemical study. These farms were visited during study period to screen the cases of chronic respiratory disease on the basis of clinical signs and symptoms like respiratory rales, open mouth breathing, ocular and nasal discharge, marked depression and weakness, decreased feed intake, feed conversion, egg production and hatchability. Out of total 16500 layer birds and 21600 broiler birds in ten farms selected for the present study, 2216 and 2346 cases of chronic respiratory disease were diagnosed in layer and broiler birds, respectively on the basis of history, clinical signs and gross pathological lesions in the dead birds. The incidence in layer was $13.42 \%$ whereas the incidence in broiler was $10.86 \%$. The incidence rate was higher in the layers than broilers. 


\section{Introduction}

Poultry typically includes chicken and ducks which is used for food or for their eggs. Poultry industry provides employment to marginal and landless farmers which constitute a large section of the society. This industry is growing at a rapid phase worldwide to meet the global demand for good quality protein (Blake et al., 2014). One of the major constraints in the development of poultry industry is the outbreak of diseases, which cause about $30 \%$ mortality of chicken every year (Ali, 1994). Among reported diseases of poultry, chronic respiratory disease is one of the important diseases as it can cause higher morbidity leading to decrease in production. Cold weather, poor air quality or crowding, concurrent infections, and some live virus vaccinations may facilitate infection, disease, and transmission. Morbidity is high and mortality is low in uncomplicated cases.

The clinical manifestations of CRD are coughing, sneezing, snicks, rales, difficulty in breathing (through partially opened beak),frothy ocular exudates and nasal discharge, conjunctivitis, decrease in feed consumption (poor weight gain) and egg production, increased mortality, poor hatchabilty, embryo pipping, increased embryo mortality and, in turkeys, swelling of infra orbital sinuses. Lameness, pale comb and head, swollen hocks and footpad are also seen (Charlton et al., 1996). Mycoplasma gallisepticum and Mycoplasma synoviae, cellwall less bacteria, are considered to be the most pathogenic strains in poultry causing chronic respiratory diseases in chickens (Buim et al., 2009 and Bradely et al., 1998). In broilers, there is reduction in weight gain of up to $20 \%$ to $30 \%$, a $10 \%$ to $20 \%$ decrease in feed conversion, a $5 \%$ to $10 \%$ mortality rate and $10 \%-20 \%$ of carcass are condemned at the processing plant. In breeders and layers, the disease causes a $10 \%$ to 205 decrease in egg production and $5 \%$ to $10 \%$ increase in embryo mortality (Stripkovits and Kempf, 1996). All the age group of chickens are susceptible but disease is more common in layers upto 32 weeks of age (Udhayavel et al., 2016). The incidence is more in layers (12.84\%) than broilers $(11.81 \%)$ (Sultana et al., 2012). Though extensive work on mycoplasmosis in birds has already been done in different states, but it was not covered in Ayodhya district of Eastern U.P. A detailed study has been done to know the incidence of chronic respiratory disease in broilers and layers in Ayodhya district of Eastern Uttar Pradesh so that mycoplasmosis could be reduced or prevented and more income can be generated by the poultry farmers.

\section{Materials and Methods}

For the present study, Broiler and layer birds affected with chronic respiratory disease were screened in 10 different private and commercial broiler flocks located in Ayodhya district of Eastern Uttar Pradesh for six months starting from October, 2018 to March, 2019. Two private farms from each tehsil of Ayodhya district were selected for the above purpose on the basis of stratified random sampling. The dead birds from ten different private farms of Ayodha district were collected. The pathological investigation was carried out at all the 10 different randomly selected farms. These farms were visited during study period to screen the cases of chronic respiratory disease on the basis of clinical signs and symptoms like respiratory rales, open mouth breathing, ocular and nasal discharge, marked depression and weakness, decreased feed intake, feed conversion, egg production and hatchability.

In addition, sometimes some sick birds were kept under careful observation with feed and water ad libitum till death to record the detail clinical signs along with other abnormalities 
and all of them were necropsied soon after death. The naturally dead birds from the above different private farms were collected during study period and brought to the Veterinary Pathology Laboratory, NDUAT, Kumarganj, Ayodhya for the postmortem examination. The post-mortem examinations were conducted thoroughly and carefully for any gross lesions in the lungs. Post mortem examination was also conducted at the farms. The lungs were collected in $10 \%$ neutral buffered formalin for further histopathological and immunohistochemical studies. The representative tissue pieces from lungs were fixed in $10 \%$ formal saline and were processed for paraffin block and sectioning into $3-5 \mathrm{~mm}$ thickness by microtome machine and were stained with heamatoxylin and eosin (H\&E) stain for histopathological examination (Luna, 1968).

\section{Results and Discussion}

The diagnosis of the disease was based on the history, clinical signs (Fig. 1) and characteristic gross lesions (Fig. 2 and 3), microscopic tissue alterations (Fig. 4) and immunohistochemical studies but only incidence of this disease in layers and broilers is discussed here. Out of total 16500 layer birds and 21600 broiler birds in ten farms selected for the present study, 2216 and 2346 cases of chronic respiratory disease were diagnosed in layer and broiler birds, respectively. The incidence in layer was $13.42 \%$ whereas the incidence in broiler was $10.86 \%$ (Table 1) which corroborated with the findings of Sultana et al., (2012), Ahmad et al., (2009) and Hasan et al., (2016) who also reported the incidence of the disease in birds ranging from 11.81 to $14.70 \%$ but was in contrast with the findings of Islam et al., (2003) who reported incidence as 5.32\%.

The mortality rate in layer was $10.51 \%$ whereas the mortality rate in broiler was $6.85 \%$ (Table 1) simulated the findings of Barua et al., (1995) who reported mortality ranging from 1.0 to $10 \%$ and but was in contrast with the findings of Jordon and Pattison (1996) as $0.82 \%, 0.44 \%$ and 1 to $2 \%$ respectively.

Fig.1 Open mouth breathing with reduced growth of bird affected with CRD

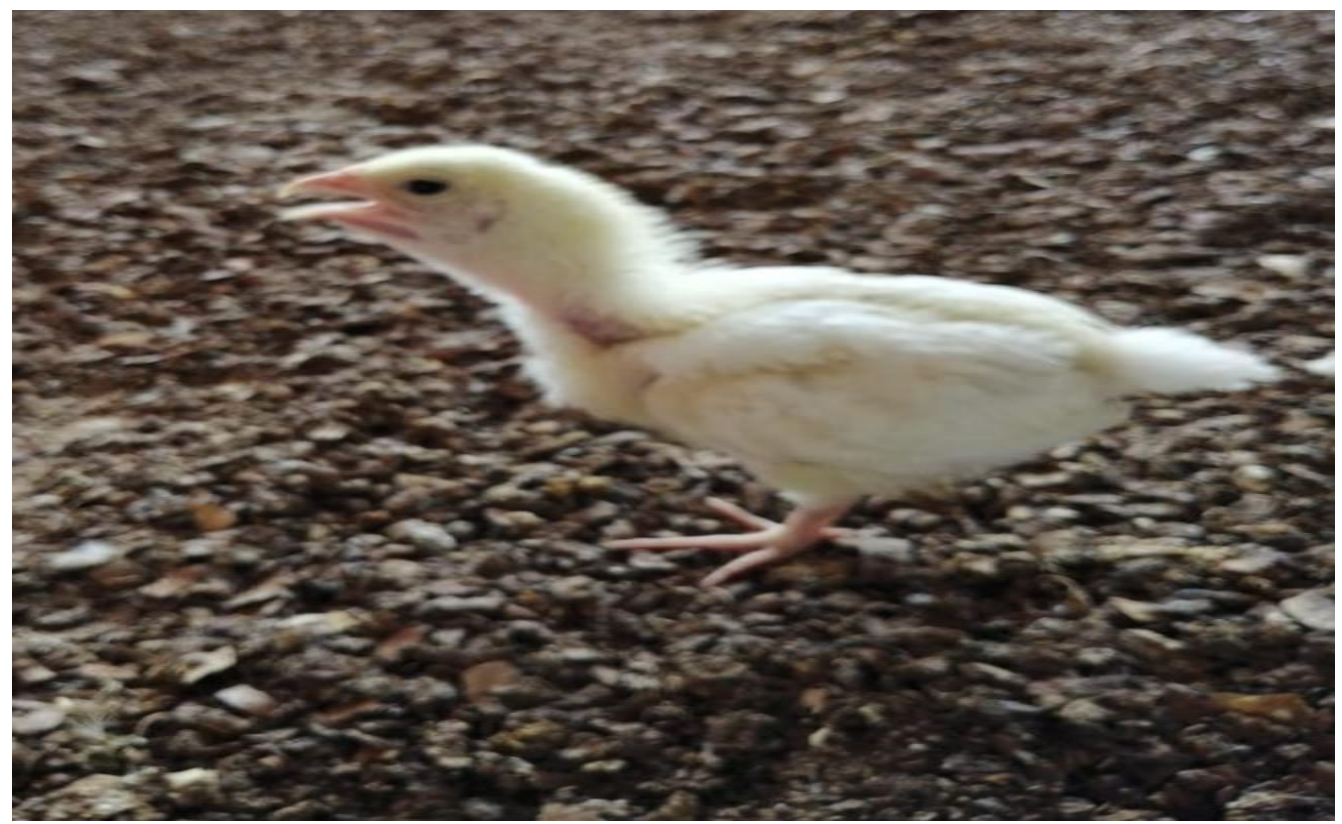


Fig.2 Severe haemorrhages in trachea of affected bird

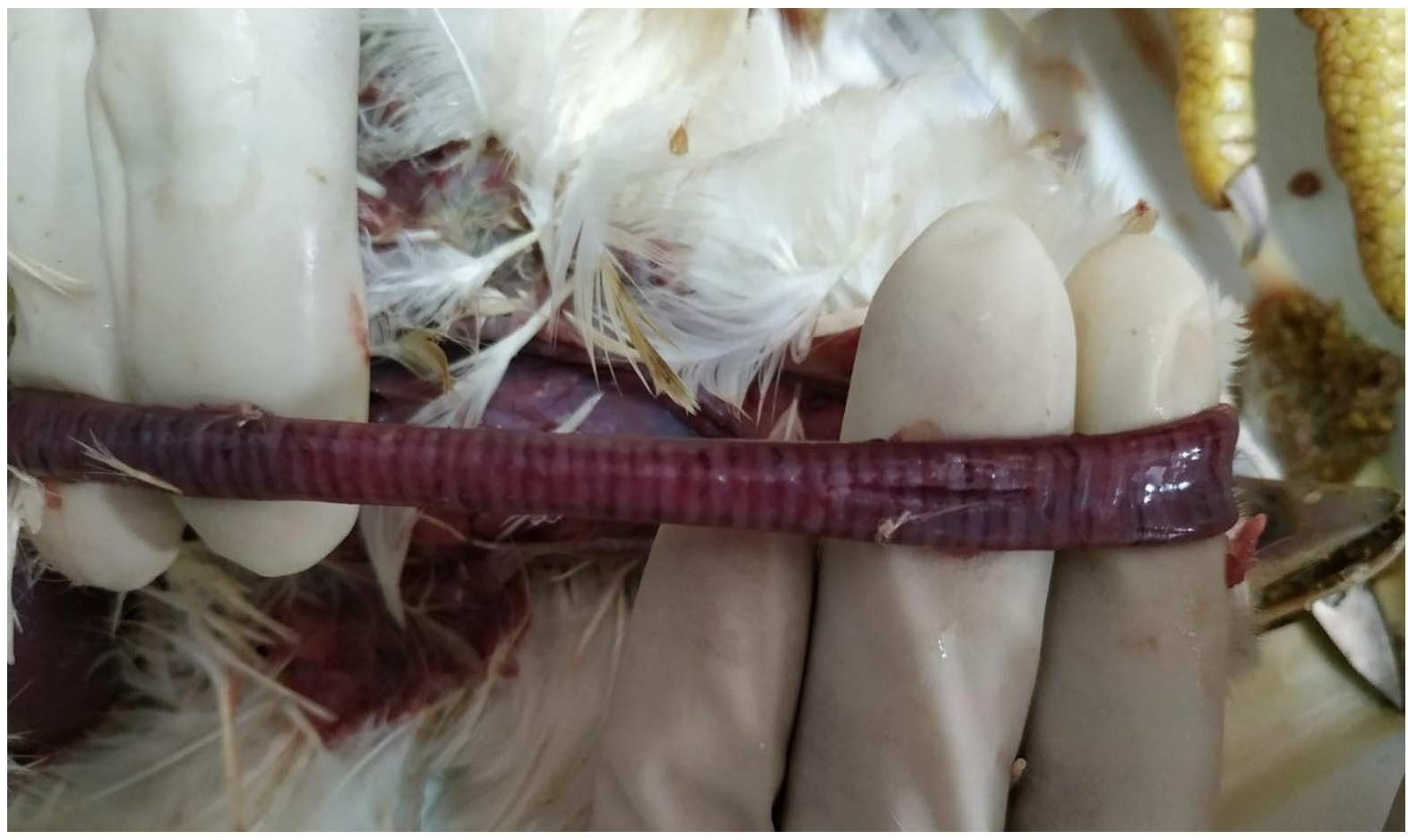

Fig.3 Thickened air sac covered with caseous exudate

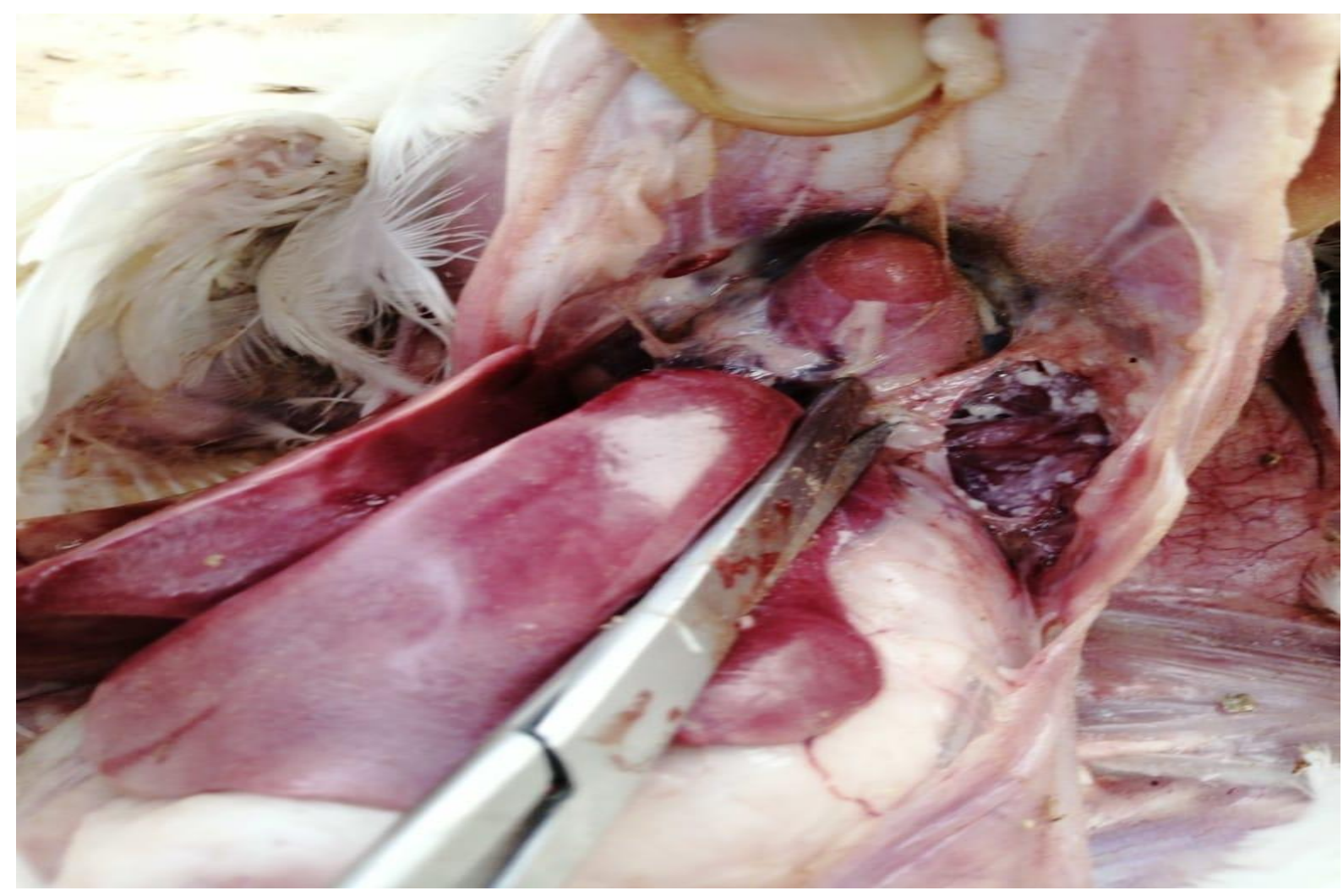


Fig.4 Oedema in the lumen of the alveoli, congestion and lymphocytic infiltration in the interstitium of lung (interstitial pneumonia) H\&E X 200

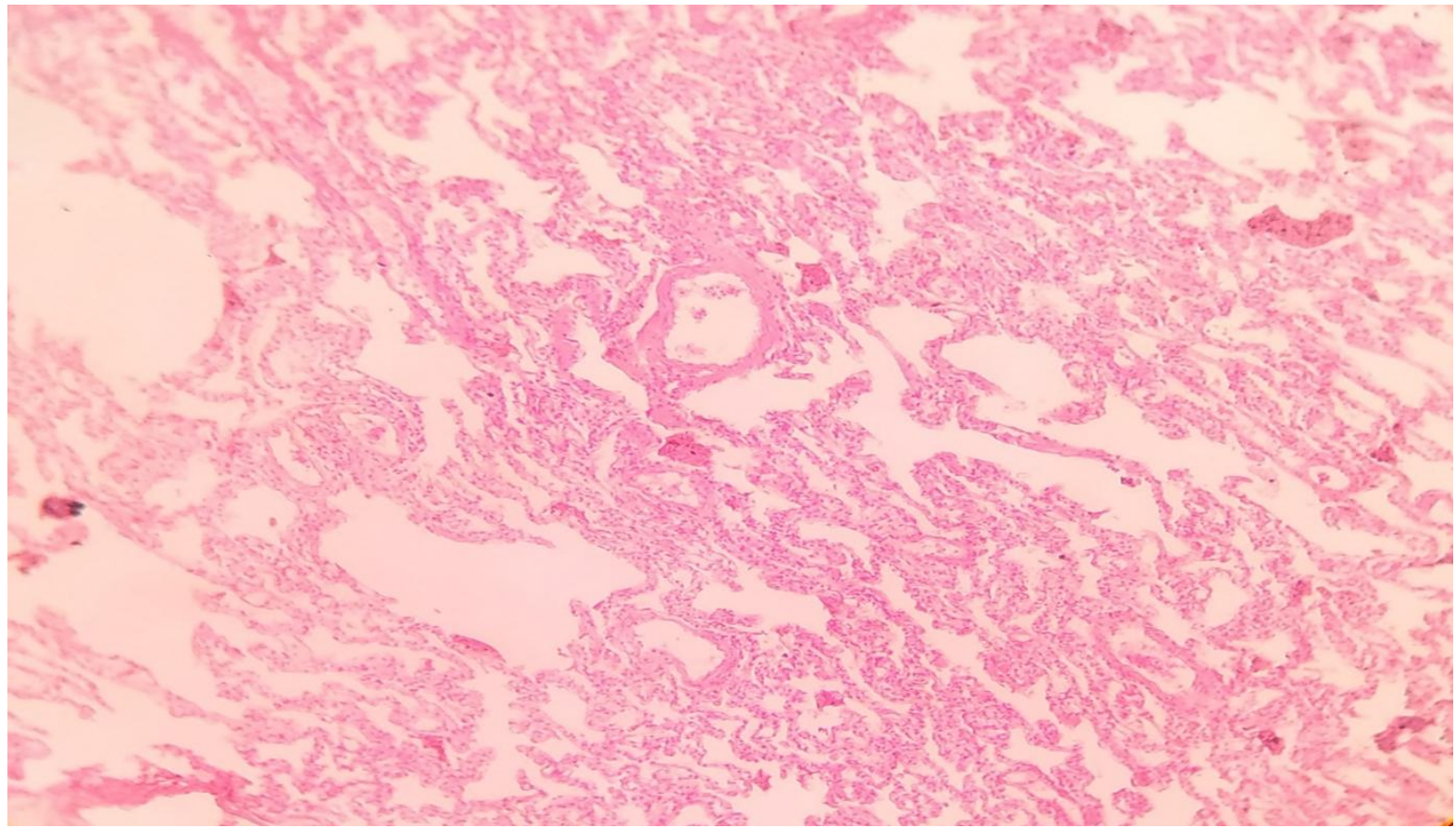

Table.1 Overall incidence, mortality rate and case fatality rate of chronic respiratory disease on the type of birds

\begin{tabular}{|l|l|l|l|l|l|l|l|l|}
\hline $\begin{array}{l}\text { S. } \\
\text { NO }\end{array}$ & $\begin{array}{l}\text { Type } \\
\text { of } \\
\text { birds }\end{array}$ & $\begin{array}{l}\text { No. of } \\
\text { farm }\end{array}$ & $\begin{array}{l}\text { Populatio } \\
\text { n of birds }\end{array}$ & $\begin{array}{l}\text { No. of } \\
\text { affected } \\
\text { birds }\end{array}$ & $\begin{array}{l}\text { Age of } \\
\text { infection }\end{array}$ & $\begin{array}{l}\text { No. of } \\
\text { birds } \\
\text { died }\end{array}$ & $\begin{array}{l}\text { Incidence } \\
(\boldsymbol{\%})\end{array}$ & $\begin{array}{l}\text { Mortality } \\
\text { rate }(\boldsymbol{\%})\end{array}$ \\
\hline $\mathbf{1}$ & Layer & 2 & 16500 & 2216 & $\begin{array}{l}23-32 \\
\text { weeks }\end{array}$ & 1734 & 13.42 & 10.51 \\
\hline $\mathbf{2}$ & Broilers & 8 & 21600 & 2346 & $\begin{array}{l}11-42 \\
\text { days }\end{array}$ & 1481 & 10.86 & 6.85 \\
\hline
\end{tabular}

Further, the highest incidence was found during fourth week in broilers and in layers ranging from 23-32 weeks (Table 1). The present observation corroborated with the observation of McMullin et al., (2004) who recorded the high incidence during 4-6 week of age. The present observation partially simulated the observation of Sikdar et al., (2005) who also recorded the more incidences during 3-4 week of age.

The present investigation throws light on the incidence of chronic respiratory disease causing mortality in layer and broiler birds in Ayodhya district of Eastern Uttar Pradesh.

These findings indicate that chronic respiratory disease is a major disease in the poultry farms causing morbidity and mortality in Ayodhya district of Eastern Uttar Pradesh but morbidity and mortality varies from farm to farm depending upon the management practices and other superimposed infections.

Tentatively diagnosed chronic respiratory disease on the basis of clinical signs and gross 
lesions can be confirmed by histopathological and immunohistochemical study and infection can be checked by proper treatment if diagnosed early. So, bird morality can be reduced or prevented and more income can be generated by the poultry farmers by regular preventive treatment using antimicrobial agents along with improved sanitation, hygiene and better husbandry practices.

\section{Acknowledgement}

The authors are thankful to the owner of private farms which were selected for the present study for their co-operation.

\section{References}

Ahmed, M.S., Sarker, A. and Rahman, M.M. (2009). Prevalence of infectious disease of broiler chickens in Gazipur district. Bangladesh Journal of Veterinary Medicine, 7 (2): 326-331.

Ali, M.J. (1994). Current status of Veterinary Biologics production in Bangladesh and their quality control. Proceedings of the BSVER symposium held on July 28, 1994 at NIPSOM Auditorium, Mohakhali, Dhaka, Bangladesh.

Blake, D.P., Tomley, F.M. (2014). Securing poultry production from the ever-present Eimeria challenge. Trends parasitol, 30:12-19.

Bradley, L.D., Snyder, D.B. and VanDeuson, R.A. (1988). Identification of species-specific polypeptides of Mycoplasma gallisepticum and Mycoplasma synoviae. Am J VetRes., 49: 511515.

Buim, M.R., Mettifogo, E., Timenetsky, J., Kleven, S. and Ferreira, A.J.P. (2009). Epidemiological survey on Mycoplasma gallisepticum and $M$. synoviae by multiplex PCR in commercial poultry. Pesquisa Veterinaria Brasileira, 29: 552-556.
Charlton, B.R., Bermudez, A.J., Boulianne, M., Ekroade, R.J., Jeffry, J.S. and Wakenell, P.S. (1996). Avian disease manual. Kennet square, Pennsylvania, USA: American Association of Avian Pathologists, 115-125.

Hassan, M.K., Kabir, M.H., Hassan, M.A.A., Sultana, S., Khokon, I. and Kabir, S.M.L. (2016). Prevalence of poultry diseases in Gazipur district of Bangladesh. Asian Journal of Medical and biological Research, 2 (1): 107112.

Islam, M.R., Das, B.C., Hossain, K., Lucky, N.S. and Mostafa, M.G. (2003). A study on the occurrence of poultry diseases in Sylhet region of Bangladesh. International Journal of Poultry Science, 2 (5): 354-356.

Jordon, F.T. (1985). Gordon memorial lecture: people, poultry and pathogenic mycoplasmas. British Poultry Science, 26 (1): 1-15.

McMullin, P. (2004). A pocket guide to poultry health and disease. Sheffield, United Kingdom: 5M Enterprises Limited. Page 123.

Sikder, A.J., Islam, M.A., Rahman, M.M. and Rahman, M.B. (2005). Sero-prevalence of Salmonella and Mycoplasma gallisepticum infection in the six model breeder poultry farms at Patualhali district of Bangladesh. International Journal of Poultry Science, 4 (11): 905-910.

Stripkovits, L. and Kempf, L. (1996). Mycoplasmosis in poultry. Rev. Sci. tech. Off. Int. Epiz., 15(4): 1495-1525.

Sultana, R., Siddique, B., Ali. R., Chaudhary, S. and Maqbool, A. (2012). A study on the prevalence of repiratory diseases in broiler and layer flock in and around Lahore district. Punjab University Journal zoology, 27 (1): 13-17.

Udhayavel, S., Murthy, T.R.G.K., Gowthaman, V., Senthivel, K. and Suresh, K.G. (2016). Detection of subclinical infection of Mycoplasma gallisepticum in commercial chicken by indirect ELISA. Adv. Anim. Vet. Sci., 4 (8): 438-440.

\section{How to cite this article:}

Gupta, R.K., D. Niyogi, J.P. Singh, Sonu Jaiswal, P.K. Chaudhary and Varun, V.K. 2019. Study on the Incidence of Chronic Respiratory Disease in Layer and Broiler Chickens in Ayodhya District of Eastern Uttar Pradesh, India. Int.J.Curr.Microbiol.App.Sci. 8(08): 13271332. doi: https://doi.org/10.20546/ijcmas.2019.808.156 